\title{
The conductivity of ERCP guide wires during direct contact with current source
}

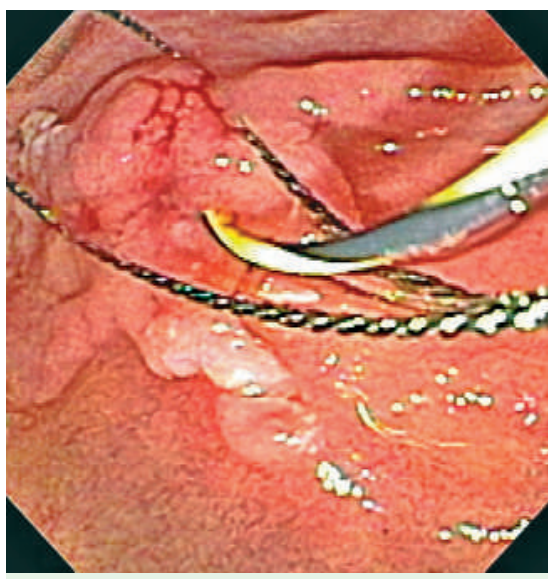

Fig. 1 Typical snare position for ampullectomy.

During wire-guided ampullectomy, the snare often directly contacts the guidewire ( Fig. 1) [1-4]. It is therefore important to know how much current the guide wire conducts. No published study in the English literature addresses this issue.

We tested the conductance of four endoscopic retrograde cholangiopancreatography (ERCP) guide wires: Jagwire 0.035, Jagwire 0.025, Hydra Jagwire 0.035 (all Microvasive Inc., Natick, Massachusetts, USA), and Zebra wire 0.035 (Olympus, Melville, New York, USA). Each wire was grounded. The energy source was an endoscopic current generator programmed to typical ampullectomy settings. A polypectomy snare was used to transmit the energy ( $\bullet$ Fig. 2).

A voltmeter was attached to the polypectomy snare to determine delivered voltage $(274 \mathrm{~V})$. The snare was then tightened around the guide wire $4 \mathrm{~cm}$ proximal to the tip of the wire. An alligator clamp connected to a voltmeter was fastened $2 \mathrm{~cm}$ from the tip of the wire. The snare was energized in the standard fashion for $8 \mathrm{~s}$ with voltage recorded every $2 \mathrm{~s}$. This process was repeated with the clamp at $1 \mathrm{~cm}$ and at $3 \mathrm{~cm}$ from the wire tip. The snare was then moved $8 \mathrm{~cm}$ from the guide-wire tip and re-tightened. Voltage was recorded at 2, 4, and $6 \mathrm{~cm}$ from the wire tip. The main outcome measure was voltage, which reflects current, at prespecified sites along each guide wire.

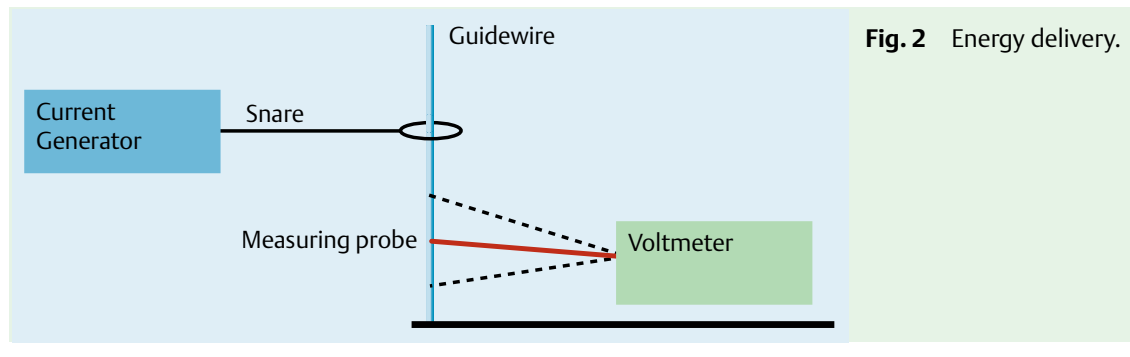

Table 1 Guide-wire voltage with snare at $4 \mathrm{~cm}$

\begin{tabular}{|lllll|}
\hline Time, $\mathbf{s}$ & Jag $\mathbf{0 . 0 3 5}$ & Jag $\mathbf{0 . 0 2 5}$ & Hydraglide & Olympus \\
\hline 0 & 18 & 18.4 & 18.4 & 18.4 \\
\hline 2 & 18 & 18.4 & 18.4 & 18.4 \\
\hline 4 & 18 & 18.4 & 18.4 & 18.4 \\
\hline 6 & 18 & 18.4 & 18.4 & 18.4 \\
\hline 8 & 18 & 18.4 & 18.4 & 18.4 \\
\hline
\end{tabular}

Table 2 Guide-wire voltage with snare at $8 \mathrm{~cm}$

\begin{tabular}{lllll} 
Time, $\mathbf{s}$ & Jag $\mathbf{0 . 0 3 5}$ & Jag $\mathbf{0 . 0 2 5}$ & Hydraglide & Olympus \\
0 & 18.4 & 18.4 & 28.8 & 18.8 \\
\hline 2 & 18.4 & 18.4 & 28.8 & 18.8 \\
\hline 4 & 18.4 & 18.4 & 28.8 & 18.8 \\
6 & 18.4 & 18.4 & 28.8 & 18.8 \\
\hline 8 & 184. & 18.4 & 28.8 & 18.8 \\
\hline
\end{tabular}

None of the guide wires conducted electricity despite being in direct contact with the snare transmitting $274 \mathrm{~V}$. A low voltage was detectable, but was constant along the length of each wire and stable over the period of energy delivery (see - Tables 1 and 2). These voltages reflect a field current which produces no appreciable heat and thus poses no risk to the patient. The differences noted in the voltages between some wires probably reflect a difference in their dielectric constants.

This ex vivo study may not perfectly reflect in vivo characteristics and assumes an undamaged guide wire.

\section{Disclaimer}

$\nabla$

The opinions and assertions contained herein are the sole views of the authors and should not be construed as official or as representing the views of the US Navy, Department of Defense, or Department of Veterans Affairs.

Endoscopy_UCTN_Code_TTT_1AR_2AJ 


\section{P. E. Young' ${ }^{1}$, P. E. Darwin ${ }^{2}$}

Uniformed Services University of Health Sciences, Division of Gastroenterology, National Naval Medical Center, Bethesda, Maryland, USA

2 Department of Medicine, Division of Gastroenterology, University of Maryland Medical System, Baltimore, Maryland, USA

\section{References}

1 Paramythiotis D, Kleeff J, Wirtz M et al. Still any role for transduodenal local excision in tumors of the papilla of Vater? J Hepatobiliary Pancreat Surg 2004; 11: 239-244

2 Bohnaker S, Seitz U, Nguyen D et al. Endoscopic resection of benign tumors of the duodenal papilla without and with intraductal growth. Gastrointest Endosc 2005; 62: $551-560$

3 Han J, Kim MH. Endoscopic papillectomy for adenomas of the major duodenal papilla. Gastrointest Endosc 2006; 63: 292 -301

4 Moon JH, Cha SW, Cho Y et al. Wire-guided endoscopic snare papillectomy for tumors of the major duodenal papilla. Gastrointest Endosc 2005; 61: 461 - 466
Bibliography

DOI $10.1055 / \mathrm{s}-2007-966830$

Endoscopy 2008; 40: E36-E37

(c) Georg Thieme Verlag KG Stuttgart · New York . ISSN 0013-726X

\section{Corresponding author}

\section{P. E. Young, MD}

National Naval Medical Center Division of Gastroenterology BLDG 9, 1st floor

Bethesda

MD 20889

USA

Fax: +1-301-295-4599

peyoungmd@hotmail.com 